\title{
TLR7/8/9 Antagonist IMO-8400
}

National Cancer Institute

\section{Source}

National Cancer Institute. TLR7/8/9 Antagonist IMO-8400. NCI Thesaurus. Code C114975.

An olig onucleotide targeted to the mRNA of MYD88 L265P, a mutant form of the linker protein MYD88, with potential antitumor activity. Anti-MYD88 oligonucleotide IMO-8400 binds to and inhibits the translation of mutated MYD88 L265P mRNA. This prevents overactivation of signaling pathways mediated by toll-like receptors (TLRs) 7, 8, and 9, nuclear factor-kappa B (NF-kB) activity, Janus-associated kinases-signal transducer and activator of transcription (JAK-STAT) signaling and the production of various cytokines. Together, this leads to an induction of apoptosis and an inhibition of tumor cell proliferation in MYD88 L265P-expressing tumor cells. MYD88, a key adaptor protein in the TLR signaling pathway, is mutated in a variety of B-cell lymphomas, including Waldenstrom's macrog lobulinemia (WM) and activated B-cell-like diffuse large B-cell lymphoma (ABC-DLBCL). 